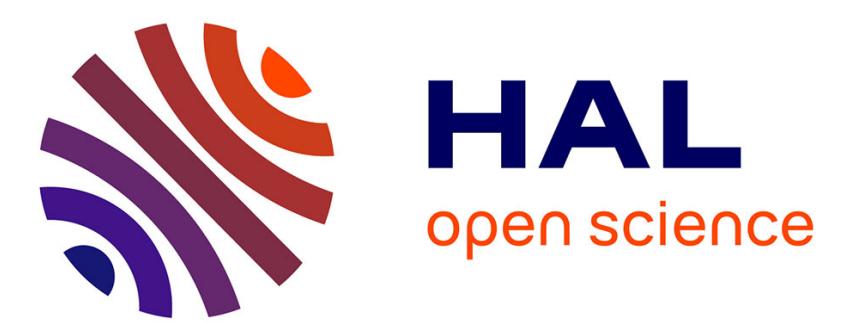

\title{
True performance: reducing stereotype threat effect in older adults' clinical assessment of memory
}

Alice Follenfant, Thierry Atzeni

\section{To cite this version:}

Alice Follenfant, Thierry Atzeni. True performance: reducing stereotype threat effect in older adults' clinical assessment of memory. Aging, Neuropsychology and Cognition, 2019, 27, pp.935 - 948. 10.1080/13825585.2019.1703893 . hal-03279368

\section{HAL Id: hal-03279368 \\ https://hal.univ-grenoble-alpes.fr/hal-03279368}

Submitted on 6 Jul 2021

HAL is a multi-disciplinary open access archive for the deposit and dissemination of scientific research documents, whether they are published or not. The documents may come from teaching and research institutions in France or abroad, or from public or private research centers.
L'archive ouverte pluridisciplinaire HAL, est destinée au dépôt et à la diffusion de documents scientifiques de niveau recherche, publiés ou non, émanant des établissements d'enseignement et de recherche français ou étrangers, des laboratoires publics ou privés. 


\title{
True performance: reducing stereotype threat effect in older adults' clinical assessment of memory
}

\author{
Alice Follenfant ${ }^{\mathrm{a}}$ and Thierry Atzeni ${ }^{\mathrm{b}}$ \\ aLaboratoire de Psychologie, EA4139, University of Bordeaux, Bordeaux, France; bLIP/PC2S, The Université \\ Grenoble Alpes, University Savoie Mont Blanc, Grenoble, France
}

\begin{abstract}
Empirical studies suggest that memory loss with age is based not only on biological, but also on contextual factors. In line with the stereotype threat (ST) theory, it is argued that the features of the standard clinical situation may contribute to an underestimation of memory performance in older adults $(\mathrm{OA})$. To prevent these shortcomings, we proposed and tested two different interventions that are easy to implement in clinical settings: individuation and selfhandicapping. Results indicate that the individuation intervention appears to be a promising solution to alleviate the ST burden in clinical assessment of memory.
\end{abstract}

\section{ARTICLE HISTORY}

Received 6 June 2019

Accepted 5 December 2019

\section{KEYWORDS}

Stereotype threat; older adults; memory; clinical assessment

A strong and culturally shared belief in many societies today is that some cognitive abilities steeply decline with age, and this is particularly true for memory performance (Cuddy, Norton, \& Fiske, 2005; Löckenhoff et al., 2009). People across the lifespan endorse this stereotype, from children to older adults (OA) themselves (e.g., Nosek, Banaji, \& Greenwald, 2002). This representation may in turn negatively affect the cognitive performance of older people. According to the stereotype threat (ST) theory (Steele, 1997), when confronted with a situation where one is at risk of confirming a self-relevant stereotype, they might paradoxically confirm this stereotype by underperforming in the related task. Since the publication of the seminal paper by Steele and Aronson (1995), numerous studies have shown how situations where the stereotype is salient can lead to poorer performance outcomes for individuals targeted by this stereotype. This effect also concerns $O A$ in situations where either their age or the memory dimension of the task is made salient by context. For example, reporting one's old age, knowing that performances will be compared with that of younger people, or even being told that $O A$ generally do worse than young adults (YA, e.g., Abrams, Eller, \& Bryant, 2006; Hess, Emery, \& Queen, 2009; Hess, Hinson, \& Hodges, 2009; Kang \& Chasteen, 2009; Mazerolle, Régner, Morisset, Rigalleau, \& Huguet, 2012) could activate the effect. Correspondingly, memory performance of OA can be improved by presenting the task as something other than as a memory test. For instance, the memory task can be presented as an orientation task (Desrichard \& Köpetz, 2005; see also, Bouazzaoui et al., 2015; Rahhal, Hasher, \& Colcombe, 2001), or can be reframed as an age-fair task (e.g., Mazerolle et al., 2012; 
Mazerolle, Régner, Rigalleau, \& Huguet, 2015), or can be an implicit memory task in order to prevent people from being aware that their memory is tested (see, Eich, Murayama, Castel, \& Knowlton, 2014; Light, Prull, La Voie, \& Healy, 2000 for a review).

Meta-analyses indicate that ST is a robust effect, with a moderate effect size for agebased ST effect ( $d=0.28$, Lamont, Swift, \& Abrams, 2015; Spencer, Logel, \& Davies, 2016). Concerning the ST effect on memory, differences in effect size have been observed, depending on the type of memory assessed: the effect of age-based ST is greater for working memory than for episodic memory $(d=.37$ and $d=.25$, respectively; Armstrong, Gallant, Li, Patel, \& Wong, 2017). However, even though ST effect is robust and largely replicated, the underlying mechanisms are not yet well understood, because ST might not be a unitary phenomenon, as was previously thought (see Barber, 2017; Shapiro \& Neuberg, 2007). These underlying mechanisms have been widely investigated, leading to multiple affective, cognitive, and motivational processes identified as potential mediators of ST effects on performance (e.g., Schmader, Johns, \& Forbes, 2008). Reviewing all of the potential mechanisms of ST effects is far beyond the scope of this paper (see Pennington, Heim, Levy, \& Larkin, 2016 for review; or Barber \& Mather, 2014 for a specific review of ST among OA). Nevertheless, there is a clear consensus on the fact that the occurrence of ST effect on performance relies on contextual factors. Situations in which either the group identity (e.g., OA) or the nature of performance (e.g., memory testing) is salient pose a risk to reduce performance in people of the stereotyped group, relative to conditions where neither the group identity nor the nature of performance is mentioned (i.e., the control or non-threatened condition).

Against this background, it is useful to closely look at clinical settings for memory assessment, as they might contain several cues to increase the effect of ST. The word "memory" is everywhere (e.g., clients expressing memory complains are addressed to a "memory" consultation in a "memory clinic"). The memory test usually appears highly relevant to the age stereotype, either through its name (memory evaluation test) or through its instructions (e.g., "I will test your memory"). Moreover, the clinician administering the test is often younger than the client, which, by contrast, may highlight the age identity of the client just before taking the memory test. In short, in a standard clinical situation, everything converges to enhance the ST effect, and therefore, to underestimate the memory performance of older clients in the assessment (see Schlemmer \& Desrichard, 2018).

The goal of this paper is to test the means to reduce the ST effect during memory assessment in OA. This is all the more important given that ST significantly decreases theperformance of $\mathrm{OA}$ in predementia screening tests. People who self-categorized as "old" and who expected general cognitive abilities to decline with age (higher-threat condition) exhibited poorer performance on a mental status examination (compared to $\mathrm{OA}$ in lower-threat conditions), resulting in dramatic clinical implications: $70 \%$ of them met diagnostic screening criteria for dementia (vs. only $14 \%$ of the OA in the lower-threat conditions; Haslam et al., 2012). Likewise, in a study showing ST effect on OAs' performance on MMSE and MoCA tests, Mazerolle et al. (2017) found that $40 \%$ of OA in the higher-threat condition met the screening criteria for dementia, compared to only $10 \%$ in the lower-threat condition. These studies highlight the risk to trigger false-positive diagnostic errors in the clinical assessment of both, memory and general cognitive abilities, and thus, the need to find ways to limit the effect of ST. 
Several studies have already tested techniques to reduce ST effect or have identified individual or contextual moderators of the ST effect, yet very few studies have focused on OA. We have reviewed these studies keeping in mind that they should fit clinical settings. Some have proposed interventions aiming at modifying the context of the task to address the negative impact of ST on performance. An ST-free context should not mention memory or age to prevent any activation of the social identity of "elderly," or a task relevant to this social identity. However, such an "age-blind" or "memory-blind" condition does not match the usual clinical setting of memory assessment and seems excessively challenging to implement. Similarly, although encouraging, the strategy of presenting a memory test as age-fair (e.g., Mazerolle et al., 2012) is not a sustainable solution in standard clinical settings, where the nature of the tests cannot be easily hidden.

Other studies have identified moderating factors that could help to draw interventions to reduce ST. However, individual moderators are challenging to manipulate. For instance, although direct intergenerational contact can reduce vulnerability to ST among OA for cognitive tasks (such as math performance, Abrams et al., 2008, 2006), it is very dependent on older people's opportunity for meaningful contact with younger people (Hewstone \& Brown, 1986). The same is true for other individual moderators of the ST effect (e.g., positive self-perception of aging, Fernandez-Ballesteros, Bustillos, \& Huici, 2015; Levy, 2009; ingroup identification, Kang \& Chasteen, 2009) that are not under the clinician's control and can be difficult to achieve in practice. Even so, some of these moderators can be manipulated by the context, which allows experimentally testing their effectiveness, and offers the possibility of active intervention. For example, asking $O A$ to imagine a positive interaction with a young stranger can lead to reducing the ST effect on math performance through reducing test-related anxiety (e.g., see Abrams et al., 2008). In the same vein, giving an easy language task prior to a memory task leads OA to perform better in the memory task, compared to OA, who had an unsuccessful or no prior task (Geraci \& Miller, 2013). These studies suggest that administrating another (imaginary contact or a successful) task prior to cognitive assessment could be useful to reduce the ST effect.

\section{The present study}

Our aim in the present study was to design and test interventions that would slightly modify the context of memory assessment (by adding a brief task prior to the memory test) in a way that could reduce the ST effect in OA. These interventions must be easy to implement in clinical settings without changing the structure and psychometric qualities of the memory assessment tests.

Drawing upon existing interventions discussed above, and on the specificity of agerelated stereotype threat, we selected two key levers to meet the challenge: the salience of age and of memory loss. As the threat experienced by OA about their memory abilities is self-concept based (Shapiro \& Neuberg, 2007), interventions need to disconnect the self from aging-identity or from memory-performance. Specifically, OA are threatened by their own risk of behaving like the stereotype (Barber, 2017). In other words, this threat is not related to others; it is a self (source)-to-self (target) threat. Thus, we test two different interventions that could each reduce the ST effect: (1) individuation of the self to alleviate 
the burden of social identity, and (2) self-handicapping to externalize the attribution of the performance.

Positive effects of individuation intervention have already been obtained on genderbased STs (Ambady, Paik, Steele, Owen-Smith, \& Mitchell, 2004; Désert, Leyens, Croizet, \& Klopfenstein, 2001; Keller \& Sekaquaptewa, 2008). Ambady et al. (2004) primed women with gender, and subsequently individuated half of them by asking a brief description of themselves. They found that women who had the opportunity to self-described performed better on a math task than those who were also primed with gender but without individuation. To our knowledge, no study has demonstrated the impact of individuation in the ST effect on the memory performance of OA. Because age-based ST is a self-concept threat, individuation should positively affect performance by disconnecting the self from the group, thereby protecting self-integrity (see Keller \& Sekaquaptewa, 2008 for the crucial role of individuation under threat). Hence, we hypothesized that an individuation manipulation (vs. no manipulation) just before a memory assessment would increase memory performance among $O A$.

Besides, people who experience a threat to their performance could minimize potential failure and, thus, protect their self by finding or creating external excuses (e.g., a lack of sleep; Jones \& Berglas, 1978). Steele and Aronson (1995) had already linked selfhandicapping to ST showing that when under ST, people tend to find excuses for their performance (see also, Croizet \& Claire, 1998). However, rather than examining selfhandicapping as a self-protective claim after a failure following stereotype threat, Brown and Josephs (1999) showed beneficial effects of externally provided handicap for performance. Women who had a bogus computer crash (i.e., provided handicap) performed better in a math test than women who did not have any excuses provided. This external handicap had no effect on men, for whom the stereotype was irrelevant (but see Keller, 2002). Thus, we hypothesized that age-based ST should be reduced when OA are provided with an easy excuse to explain their potential poor memory performance, as this handicap would offer an external attribution for prospective failure, instead of an internal attribution that would threaten the self.

Overall, we expect the ST effect that are typically observed in standard clinical like condition (e.g., Régner et al., 2016) to be alleviated when an individuation intervention and/or a self-handicap intervention is added just before the memory test, resulting in better memory performance in one or both intervention conditions, compared to a nointervention control condition (i.e., the usual standardized clinical procedure of the test).

\section{Method}

\section{Participants}

Our original sample consisted of 90 volunteer participants (45 OA and 45 YA). Young participants (18-35 years old) were undergraduate students participating in this study as partial fulfillment of a course requirement. Older participants, aged above 60 years, were partly recruited from the Université du Temps Libre and partly from contacts at local social or leisure clubs. Following preset criteria, data were excluded due to MMSE scores below 26 ( $n=3$; Kalafat, Hugonot-Diener, \& Poitrenaud, 2003), or to psychological follow-up combined with anxiolytic and/or antidepressant medication $(n=2)$. All participants were 
native French speakers. The final sample consisted of 40 older $\left(M_{\mathrm{age}}=67.03 ; S D=5.39\right)$ and 45 young $\left(M_{\text {age }}=23.21 ; S D=3.56\right)$ adults (see participant characteristics in Table 1$)$.

\section{Material and procedure}

All participants were told that they would receive a memory test. They were then tested individually in two phases administered by two different experimenters (out of a total of three experimenters).

In the first phase, participants signed an informed consent and filled in a short questionnaire corresponding to a randomly assigned experimental condition: individuation intervention, self-handicapping intervention, or no-intervention (i.e., clinical standard). All three questionnaires were similar in length and type of questions (three quantitative questions answered on 10-point scales, and three open qualitative ones answered with a few words), but differed in content. In the individuation intervention, participants answered an anonymous questionnaire about themselves (their leisure activities, moral values, and personality traits). This intervention was based on Ambady et al. (2004) to activate individual identity. For the self-handicapping intervention, questions were related to the participant's lifestyle (e.g., Over the past week, on an average, how many hours have you slept per night?). Next, the experimenter pretended to quickly analyze their answers and provide a false feedback (saying: "According to your results, I note that you are not in the best conditions to take this memory test, and your performance will surely not be as good as it really is. It is almost certain that in reality, your performance would be better than what my colleague will measure today. But never mind, the most important part is that I know it, and will transmit this information to her so that she will take it into account for the analysis of the results") meant to provide an excuse for the future performance in order to externalize potential failure (see, Brown \& Josephs, 1999). In the no-intervention condition, a similar questionnaire was administered but without any link either to the self or to performance. Questions, allegedly collected for the purpose of another study, were related to television usage by French people (e.g., "How much time do you think French people spend watching TV every day?"). There was no time limit for completing the questionnaire.

In the second phase, another experimenter, blind to the participant's condition, took over to administer the memory test (RI-48, Adam, Van der Linden, Poitrenaud, Kalafat,\& membres du GREMEM, 2004). The use of two different experimenters was crucial to avoid experimenter bias in the memory assessment. It was also useful to present the two phases of the experiment as two different studies to our participants (i.e., cover story). The RI-48 is a two-phase cued-recall test with 48 items (12 semantic categories of four items each), based on a "double memory test" (Buschke, Sliwinski, Kuslansky, \& Lipton, 1995, 1997). First, words are presented to the participant 4 by 4 , on 12 separate sheets. The participant has to retrieve the word associated with each category indicated by the experimenter. In the second phase, after a 20-s distracting task (counting backward), the participant has to recall the names of the different items associated with each of the 12 categories presented one by one by the experimenter in a predetermined order. The Rl-48 gives two main performance indices, an Immediate Cued-Recall index (ICR, end of the first phase), which allows controlling the effectiveness of semantic encoding, and a Delay Cued-Recall (DCR, end of the second phase), which assesses retrieval abilities. The latter is an index of 


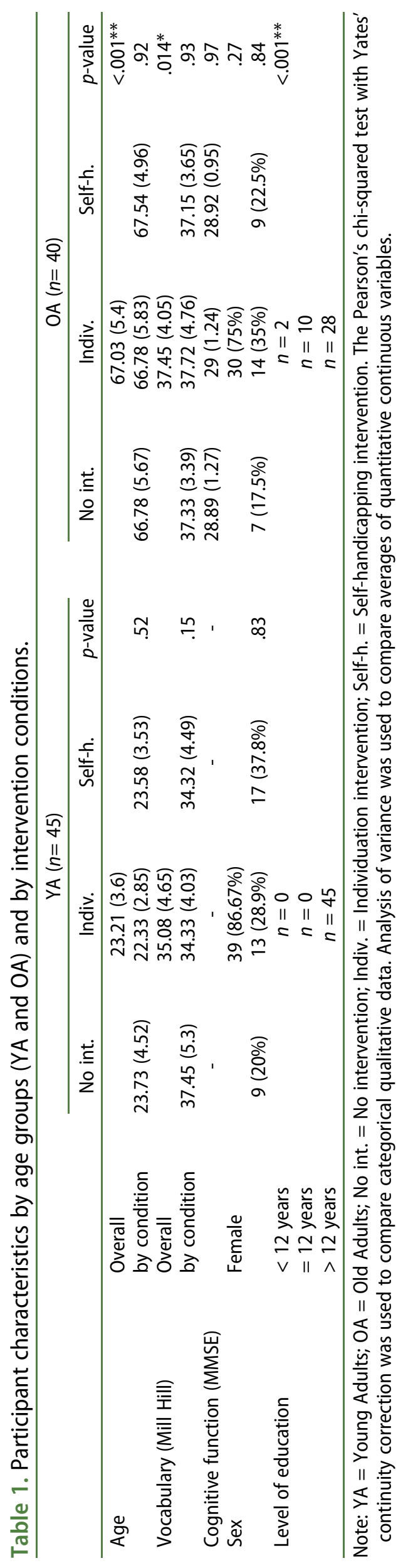


interest, as it is a measure of retrieval in episodic memory, a core process involved in many neurodegenerative diseases and thus, largely used in clinical assessment.

Finally, the vocabulary levels of all participants were assessed (Mill Hill vocabulary test, Deltour, 1993) and the MMSE (Mini-Mental State Examination, Kalafat et al., 2003) was administered to $O A$ to assess their overall cognitive functioning. All participants filled a socio-demographic questionnaire and were, then, fully debriefed and thanked.

\section{Results}

Multiple linear regression analyses were used to test whether the performance on the DCR (Delay Cued-Recall) index of old adults, compared to young adults, was significantly improved under either individuation and/or self-handicapping intervention, compared to the no-intervention condition. Five variables were created using dummy coding. In the first dummy variable, age group, the code 0 stood for YA while for OA the code was 1 . The condition in which the test was taken was coded in two other dummy variables: one for the individuation intervention and one for the self-handicapping intervention. The nointervention condition was coded as 0 in each of these two dummy variables. Finally, two last interaction term variables were created: one aimed at testing the effect of individuation by analyzing the interaction between age group (OA vs. YA) and intervention condition (individuation vs. no-intervention), and the second one, aimed thesting the effect of self-handicapping, analyses the interaction between age group (OA vs. YA) and intervention condition (self-handicapping vs. no-intervention). The five dummy variables were entered simultaneously in the model. In order not to inflate the type I error rate, the ICR score of participants was not entered in the model as a covariate (Simmons, Nelson, \& Simonsohn, 2011). Reference condition (i.e., the intercept) was the mean of young adults in the no-intervention condition.

Results showed differences in memory performance between young and old adults, depending on the prior intervention (see Figure 1). The first interaction between age group (OA vs. YA) and intervention (individuation vs. no-intervention) was significant, $B=7.91, p=.019,95 \% \mathrm{Cl}[1.28,14.54], g=1.08^{1}$. As expected, we observed a better memory performance in $Y A(M=32.64, S D=5.8)$ than in $O A(M=23.33, S D=4.6)$ in the no-intervention control condition, which is the closest to a standard clinical memory assessment condition. On the other hand, in the individuation condition, OA performed as well as YA (Ms $=29.94$ and $31.33, S D s=6.68$ and 6.45 , respectively). Among $\mathrm{OA}$, those who had the individuating intervention prior to the memory test outperformed those who had no intervention (Ms $=29.94$ vs. $23.33, t(1,25)=2.76 ; p=$ $.01)$, suggesting that this intervention has been effective to boost performance, probably by alleviating the social threat of the aging stereotype.

Conversely, the self-handicapping intervention did not help OA to maintain good memory performance, as evidenced by the difference in means: the DCR performance between the young and old adults was still important in the self-handicapping, compared to no-intervention condition, $B=3.43, p=.31,95 \% \mathrm{Cl}[-3.27,10.14], g=0.38$. The OA who had the self-handicapping intervention prior to the memory test did not perform better than the OA in the no-intervention condition ( $M s=25.08$ vs. $23.33, t(1,20)=0.83, p=.42$ ). Unlike individuation intervention, self-handicapping intervention does not appear to have resulted in any benefit. 


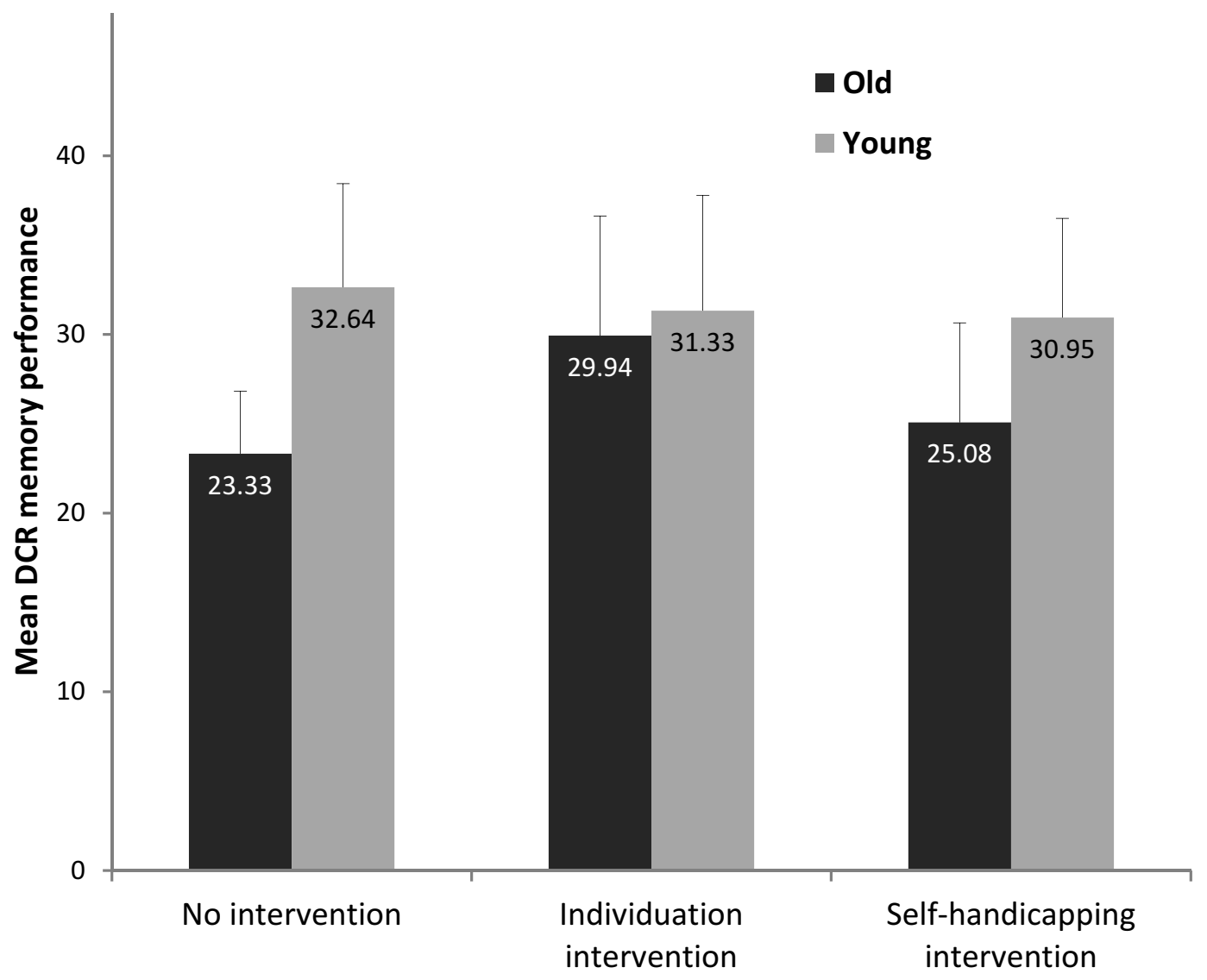

Figure 1. Mean of words correctly recalled (delay cued-recall) by younger and older participants in each condition of the intervention administered prior to the test. Error bars represent standard error.

Post-hoc analyses (using Tukey's HSD) have shown that YA performed better than OA only in the no-intervention condition ( $p=.009,95 \% \mathrm{Cl}[1.62,16.98])$. Differences in the DCR performances between $Y A$ and $O A$ were not statistically significant in the individuation intervention condition $(p=.98,95 \% \mathrm{Cl}[-4.58,7.36])$, or in the self-handicapping intervention condition ( $p=.07,95 \% \mathrm{Cl}[-13.59,0.37])$. It should be noted that among YA, no significant differences were found between the three conditions (all $p s>.90$ ).

Following a useful comment by a reviewer on a previous version of this paper, additional analyses were carried out on the ICR index. The ICR is an index that allows controlling for the memory encoding efficiency, a process that can be disrupted by ST (Wong \& Gallo, 2018). If so, similar results to those obtained on the DCR index should be observed. The pattern of the result was descriptively similar to that obtained for the DCR index. However, no significant effect was found (all $p s>.37$ ), presumably because of ceiling effects.

\section{Discussion}

Stereotype threat effects in OAs' memory performance in clinical assessment are now well known (e.g., Barber, Mather, \& Gatz, 2015; Fresson, Dardenne, Geurten, \& Meulemans, 2017; Hess, Auman, Colcombe, \& Rahhal, 2003). Yet, little effort has been made to reduce it. This was precisely the goal of the present study, and this was done by testing the efficacy of two different interventions: individuation and self-handicapping. If either or 
both of these interventions can reduce the effect of ST, then we should observe better memory performance in older people after the intervention than without intervention.

Results showed that memory performance of OA was lower in the no-intervention clinical-like condition than in the individuation condition, whereas the performance of YA (for whom the situation is not a threat to their performance) remained unchanged. In line with our hypotheses, individuation may have alleviated the threat by enhancing individual identity, bringing it above the social identity of being "elderly," just before taking the memory test. This way, compared to their social identity, their individual identity is less relevant to memory performance, less threatening and, therefore, has less of a negative effect on performance. In other words, part of memory impairment resulting from ST effect has probably been removed, or at least been weakened, by individuation induction (Ambady et al., 2004). This interpretation is in line with the conception of stereotype threat in terms of self-concept for OA (Barber, 2017); that is, OA worry that the agestereotype could be true for themselves, personally. Another interpretation could be in terms of self-affirmation, which refers to the process by which self-esteem is restored or protected in situations that threaten self-integrity (Steele, 1998). Self-affirmation can protect against identity threats, including stereotype threats (e.g., Kinias \& Sim, 2016). In the present study, if participants spontaneously cited only positive attributes in their responses to open questions about their personality traits, then it could be selfaffirmative. Although this is unlikely given the nature of the answers to the other questions (favorite leisure activities and moral values), we cannot rule out this alternative interpretation. However, whether there are one (individuation) or two (individuation and self-affirmation because of only positivity self-traits) possible explanations of ST, its effect on performance is still the same, and is in the expected direction. Furthermore, Ambady et al. (2004) have addressed this point by asking their participants to list more negative traits than positive ones (Study 1b); they observed the same results on performance in their women participants as when asking for equal number of positive and negative traits (Study 1a). It seems that individuation offers OA the possibility to affirm their worth in another domain and, thus, reminding them that their self-identity is not tied only to the threatened one (see Barber, 2017). This shows that individuation is sufficient to boost performance in the stereotype-threatened participants.

In contrast, the self-handicapping intervention did not have the expected effects on performance, as it did not help to improve the memory performance of OA. We presumed that allowing older participants to externalize their potential failure in the test could help decrease the threat (whereas this might not hold true among YA because they are not specifically threatened by the memory task) and maintain their performance higher than in the no-intervention condition (Brown \& Josephs, 1999). This was not the case. It seems that, in this case, providing older participants with an excuse for poor performance to reduce the burden of the memory test did not lead them to perform any better. Perhaps our manipulation was not sufficiently explicit or credible. Another possibility is that a selfhandicapping intervention would not be well adapted to this population or to this specific memory task. As already mentioned before, the ST effect has different underlying mechanisms depending on the specific stereotypes and performances at stake in a given situation (Barber \& Mather, 2014). And that was one of the reasons why we initially chose to test two different interventions; we figured that not all of them are adapted to the same groups and to the same performance in fighting ST effects. This is 
probably the main reason why inconsistencies remain in the results, and in the moderators and processes of ST effects identified in the literature (see Barber \& Mather, 2014; Pennington et al., 2016). Probably different processes are responsible for the ST effect, depending on the specificity of the stereotyped group (e.g., African-Americans, women, $\mathrm{OA})$, as well as on the specificity of the performance (e.g., verbal, math, or memory) considered. For instance, although executive control interference seems to be a key factor in ST effect in adults (Schmader et al., 2008), its role remains unclear for OA (Barber \& Mather, 2014). In fact, it is possible that, in the specific case of OA and performance on memory, the self-handicapping intervention is not well adapted, whereas the individuation one could be a better choice. These two interventions tackle different aspects of the stereotype threat: individuation intervention focuses on the relationship between the stereotype and the self (trying to reduce the perceived applicability of the stereotype to the self), whereas the self-handicapping one targets the relation between the performance and the self (trying to reduce the attribution of the performance to the self). It is possible that, regarding the memory performance of $\mathrm{OA}$, interventions designed to move self-perception from social identity to personal identity might be more appropriate to reduce ST effects and thus, heightens performance.

Although encouraging, these findings have some limitations. The study would benefit from replications. The sample size is quite small and a larger test of the individuation intervention effect is necessary before one can consider implementing it in clinical settings. In addition, in the present study, as the MMSE is administrated at the end (in order not to bias our measure of interest), we cannot rule out the possibility of carry-over effects from the stereotype threat manipulation. Future studies should screen OAs' general cognitive functioning several days before the intervention and the memory assessment. Moreover, it would be of interest to test this intervention on people who present low MMSE scores, as they are obviously the ones who attend memory consultations the most.

Moreover, the next step should add an exploration of the mediators of this effect. It is likely that the perception of the self (social vs. individual self) underlies the individuation effect. The processes by which these self-perceptions lead to different performances need to be explored more precisely in future research. Nevertheless, although further investigations are needed to identify the precise processes underlying the effect, our results offer the first demonstration of the potential for reducing ST effect in memory assessment, as applicable in clinical settings. These encouraging results show that ST effect on memory performance in $\mathrm{OA}$ is not a fate in clinical memory assessment situations. It can be avoided, or at least reduced, by intervention easy to implement. The individuation intervention (compared to the self-handicapping one) seems to be both, the most promising in terms of effectiveness, and the easiest to implement in clinical settings. Indeed, it appears feasible to integrate questions about the individual-self (e.g., personal values, personality traits) during a clinical interview just before the memory assessment. It is not the stereotype itself that threatens performance, but the idea, in a given situation, that it could apply to oneself. Therefore, even if stereotype about old age is deeply rooted in society (as memory loss), and may, therefore, be hard to have people think that it is wrong, it seems easier to make them think that the stereotype does not apply to them specifically. This could help reaching memory assessment closer to its biological impairment, by ridding out the aspect of the impairment due to stereotype. This small individuation intervention could be very useful for 
professionals who need an accurate measurement of memory impairment of OA for diagnostic purposes. Thus, being able to lift the stereotype threat effect during memory assessment in OA may have important clinical implications for professionals, and should be particularly helpful regarding the specific cases of mild cognitive impairment (MCl). A small individuation intervention with OA just before taking a memory test may be enough to make a big change in performance and perhaps also in the resulting clinical decisions for OA.

\section{Note}

1. Adjusted standardized mean difference effect size Hedges' $g$ was computed instead of Cohen's $d$ because of unequal sample size between conditions.

\section{Acknowledgments}

The authors thank Emmanuelle Babot, Laure Mercier, and Almeena Nandjee-Samdjee for their help with the data collection on a draft of this paper while they were graduate students in the department of psychology at the University of Bordeaux. The authors are very grateful to François Ric for his useful comments on earlier versions of this manuscript and to Sarah Barber and another anonymous reviewer for their help in improving this paper.

\section{Disclosure statement}

No potential conflict of interest was reported by the authors.

\section{References}

Abrams, D., Crisp, R. J., Marques, S., Fagg, E., Bedford, L., \& Provias, D. (2008). Threat inoculation: Experienced and imagined intergenerational contact prevents stereotype threat effects on older people's math performance. Psychology and Aging, 23, 934-939.doi:10.1037/a0014293

Abrams, D., Eller, A., \& Bryant, J. (2006). An age apart: The effects of intergenerational contact and stereotype threat on performance and intergroup bias. Psychology and Aging, 21, 691-702.doi: 10.1037/0882-7974.21.4.691

Adam, S., Van der Linden, M., Poitrenaud, J., \& Kalafat, M., et les membres du GREMEM. (2004). L'épreuve de rappel indicé à 48 items (RI-48). In M. Van der Liden, S. Adam, A. Agniel, C. Baisset Mouly, et al. (Eds.), L'évaluation des troubles de la mémoire: Présentation de quatre tests de mémoire épisodique (avec leur étalonnage). Marseille: Solal.doi: 10.1016/S0035-3787(05)84990-2

Ambady, N., Paik, S. K., Steele, J., Owen-Smith, A., \& Mitchell, J. P. (2004). Deflecting negative self-relevant stereotype activation: The effects of individuation. Journal of Experimental Social Psychology, 40, 401-408. doi:10.1016/j.jesp.2003.08.003

Armstrong, B., Gallant, S. N., Li, L., Patel, K., \& Wong, B. I. (2017). Stereotype threats effects on older adults' episodic and working memory: A meta-analysis. The Gerontologist, 57, 193-205.doi: 10.1093/geront/gnx170

Barber, S. J. (2017). An examination of age-based stereotype threat about cognitive decline: Implications for stereotype-threat research and theory development. Perspectives on Psychological Science, 12, 62-90. doi:10.1177/1745691616656345

Barber, S. J., \& Mather, M. (2014). Stereotype threat in older adults: When and why does it occur, and who is most affected? In P. Verhaeghen \& C. Hertzog (Eds.), The Oxford Handbook of emotion, social cognition, and problem solving during adulthood (pp. 302-320). Oxford, UK: Oxford University Press. 
Barber, S. J., Mather, M., \& Gatz, M. (2015). How stereotype threat affects healthy older adults' performance on clinical assessments of cognitive decline: The key role of regulatory fit. Journals of Gerontoloty. Series B, Psychological Sciences and Social Science, 6, 891-900. doi:10.1093/geronb/ gbv009

Bouazzaoui, B., Follenfant, A., Ric, F., Fay, S., Croizet, J., Atzeni, T., \& Taconnat, L. (2015). Ageingrelated stereotypes in memory: When the beliefs come true. Memory, 24, 659-668. doi:10.1080/ 09658211.2015 .1040802

Brown, R. P., \& Josephs, R. A. (1999). A burden of proof: Stereotype relevance and gender differences in math performance. Journal of Personality and Social Psychology, 76, 246-257.doi: 10.1037// 0022-3514.76.2.246

Buschke, H., Sliwinski, M., Kuslansky, G., \& Lipton, R. B. (1995). Aging, encoding specificity, and memory change in the double memory test. Journal of the International Neuropsychological Society, 1, 483-493.doi: 10.1017/s1355617700000576

Buschke, H., Sliwinski, M., Kuslansky, G., \& Lipton, R. B. (1997). Diagnosis of early dementia by the double memory test: Encoding specificity improves diagnostic sensitivity and specificity. Neurology, 48, 989-997.doi: 10.1212/wnl.48.4.989

Croizet, J.-C., \& Claire, T. (1998). Extending the concept of stereotype threat to social class: The intellectual underperformance of students from low socioeconomic backgrounds. Personality and Social Psychology Bulletin, 24, 588-594.doi: 10.1177/0146167298246003

Cuddy, A. J. C., Norton, M. I., \& Fiske, S. T. (2005). This old stereotype: The pervasiveness and persistence of the elderly stereotype. Journal of Social Issues, 61, 265-283. doi:10.1111/j.15404560.2005.00405.x

Deltour, J. J. (1993). Echelle de vocabulaire de Mill Hill de JC Raven. Adaptation française et normes comparées du Mill Hill et du standard progressive matrice (PM 38) manuel (JC Raven's Mill Hill vocabulary scale. French adaptation and standards compared of Mill Hill and the Standard Progressive Matrix (PM 38)). Braine-le-Château: Editions I'application des techniques modernes.

Désert, M., Leyens, J.-P., Croizet, J.-C., \& Klopfenstein, T. (2001). Reducing stereotype threat through re-individuation (Unpublished manuscript).

Desrichard, O., \& Köpetz, C. (2005). A threat in the elder: The impact of task-instructions, self-efficacy and performance expectations on memory performance in the elderly. European Journal of Social Psychology, 35, 537-552. doi:10.1002/ejsp.249

Eich, T. S., Murayama, K., Castel, A. D., \& Knowlton, B. J. (2014). The dynamic effects of age-related stereotype threat on explicit and implicit memory performance in older adults. Social Cognition, 32, 559-570. doi:10.1521/soco.2014.32.6.559

Fernandez-Ballesteros, R., Bustillos, A., \& Huici, C. (2015). Positive perception of aging and performance in a memory task: Compensating for stereotype threat? Experimental Aging Research, 41, 410-425. doi:10.1080/0361073x.2015.1053757

Fresson, M., Dardenne, B., Geurten, M., \& Meulemans, T. (2017). The effect of stereotype threat on older people's clinical cognitive outcomes: Investigating the moderating role of dementia worry. The Clinical Neuropsychologist, 31, 1306-1328. doi:10.1080/13854046.2017.1307456

Geraci, L., \& Miller, T. M. (2013). Improving older adults' memory performance using prior task success. Psychology and Aging, 28, 340-345.doi: 10.1037/a0030332

Haslam, C., Morton, T. A., Haslam, A., Varnes, L., Graham, R., \& Gamaz, L. (2012). "When the age is in, the wit is out": Age-related self-categorization and deficit expectations reduce performance on clinical tests used in dementia assessment. Psychology and Aging, 27, 778-784. doi:10.1037/ a0027754

Hess, T. M., Auman, C., Colcombe, S. J., \& Rahhal, T. A. (2003). The impact of stereotype threat on age differences in memory performance. Journal of Gerontology: Psychological Sciences, 58, 3-11. doi:10.1093/geronb/58.1.P3

Hess, T. M., Emery, L., \& Queen, T. L. (2009). Task demands moderate stereotype threat effects on memory performance. The Journals of Gerontology, Series B: Psychological Sciences and Social Sciences, 64, 482-486. doi:10.1093/geronb/gbp044 
Hess, T. M., Hinson, J. T., \& Hodges, E. A. (2009). Moderators of and mechanisms underlying stereotype threat effects on older adults' memory performance. Experimental Aging Research, 35, 153-177. doi:10.1080/03610730802716413

Hewstone, M., \& Brown, R. J. (1986). Contact is not enough: An inter- group perspective on the "contact hypothesis.". In M. Hewstone \& R. Brown (Eds.), Contact and conflict in intergroup encounters (pp. 1-44). Oxford, UK: Blackwell.

Jones, E. E., \& Berglas, S. (1978). Control of attributions about the self through self-handicapping strategies: The appeal of alcohol and the role of underachievement. Personality and Social Psychology Bulletin, 4, 200-206. doi:10.1177/014616727800400205

Kalafat, L., Hugonot-Diener, L., \& Poitrenaud, J. (2003). Standardisation et étalonnage français du « Mini mental state » version Greco. Neuropsychology Review, 13, 209-236.

Kang, S. K., \& Chasteen, A. L. (2009). The moderating role of age group identification and perceived threat on stereotype threat among older adults. International Journal of Aging \& Human Development, 69, 201-220. doi:10.2190/AG.69.3

Keller, J. (2002). Blatant stereotype threat and women's math performance: Self-handicapping as a strategic means to cope with obtrusive negative performance expectations. Sex Roles, 47, 193-198. doi:10.1023/A:1021003307511

Keller, J., \& Sekaquaptewa, D. (2008). Solo status and women's spatial test performance: The role of individuation tendencies. European Journal of Social Psychology, 38, 1044-1053. doi:10.1002/ ejsp.490

Kinias, Z., \& Sim, J. (2016). Facilitating women's success in business: Interrupting the process of stereotype threat through affirmation of personal values. Journal of Applied Psychology, 11, 1585-1597. doi:10.1037/apl0000139

Lamont, R. A., Swift, H. J., \& Abrams, D. (2015). A review and meta-analysis of age-based stereotype threat: Negative stereotypes, not facts, do the damage. Psychology and Aging, 30, 180-193. doi:10.1037/a0038586

Levy, B. R. (2009). Stereotype embodiment: A psychosocial approach to aging. Current Directions in Psychological Science, 18, 332-336. doi:10.1111/(ISSN)1467-8721

Light, L. L., Prull, M. W., La Voie, D., \& Healy, M. R. (2000). Dual-process theories of memory in older age. In T. J. Perfect \& E. A. Maylor (Eds.), Models of cognitive aging (pp. 238-300). Oxford, UK: Oxford University Press.

Löckenhoff, C. E., De Fruyt, F., Terracciano, A., McCrae, R. R., De Bolle, M., Costa, P. T., ... Yik, M. (2009). Perceptions of aging across 26 cultures and their culture-level associates. Psychology and Aging, 24, 941-954. doi:10.1037/a0016901

Mazerolle, M., Régner, I., Barber, S., Paccalin, M., Miazola, A.-C., Huguet, P., \& Rigalleau, F. (2017). Negative aging stereotypes impair performance on brief cognitive tests used to screen for predementia. Journals of Gerontoloty. Series B, Psychological Sciences and Social Sciences, 72, 932-936. doi:10.1093/geronb/gbw083

Mazerolle, M., Régner, I., Morisset, P., Rigalleau, F., \& Huguet, P. (2012). Stereotype threat strengthens automatic recall and undermines controlled processes in older adults. Psychological Science, 23, 723-727. doi:10.1177/0956797612437607

Mazerolle, M., Régner, I., Rigalleau, F., \& Huguet, P. (2015). Stereotype threat alters the subjective experience of memory. Experimental Psychology, 62, 395-402. doi:10.1027/1618-3169/a000303

Nosek, B. A., Banaji, M. R., \& Greenwald, A. G. (2002). Harvesting implicit group attitudes and beliefs from a demonstration web site. Group Dynamics: Theory, Research, and Practice, 6, 101-115. doi:10.1037/1089-2699.6.1.101

Pennington, C. R., Heim, D., Levy, A. R., \& Larkin, D. T. (2016). Twenty years of stereotype threat research: A review of psychological mediators. PLoS One, 11, e0146487. doi:10.1371/journal. pone. 0146487

Rahhal, T. A., Hasher, L., \& Colcombe, S. J. (2001). Instructional manipulations and age differences in memory: Now you see them, now you don't. Psychology and Aging, 4, 697-706. doi:10.1037// 0882-7974.16.4.697

Régner, I., Mazerolle, M., Alescio-Lautier, B., Clarys, D., Michel, B., Paccalin, M., ... Huguet, P. (2016). Aging stereotypes must be taken into account for the diagnosis of prodromal and early 
Alzheimer disease. Alzheimer Disease and Associated Disorders, 30, 77-79.doi: 10.1097/ wad.0000000000000129

Schlemmer, M., \& Desrichard, O. (2018). Is medical environment detrimental to memory? A test of a white coat effect on older people's memory performance. Clinical Gerontologist, 41, 77-81. doi:10.1080/07317115.2017.1307891

Schmader, T., Johns, M., \& Forbes, C. (2008). An integrated process model of stereotype threat effects on performance. Psychological Review, 115, 336-356.doi: 10.1037/0033-295x.115.2.336

Shapiro, J. R., \& Neuberg, S. L. (2007). From stereotype threat to stereotype threats: Implications of a multi-threat framework for causes, moderators, mediators, consequences, and interventions. Personality and Social Psychology Review, 11, 107-130. doi:10.1177/1088868306294790

Simmons, J. P., Nelson, L. D., \& Simonsohn, U. (2011). False-positive psychology. Undisclosed flexibility in data collection and analysis allows presenting anything as significant. Psychological Science, 22, 1359-1366.doi: 10.1037/e519702015-014

Spencer, S. J., Logel, C., \& Davies, P. G. (2016). Stereotype threat. Annual Review of Psychology, 67, 415-437. doi:10.1146/annurev-psych-073115-103235

Steele, C. M. (1997). A threat in the air: How stereotypes shape intellectual identity and performance. American Psychologist, 52, 613-629. doi:10.1037/0003-066X.52.6.613

Steele, C. M. (1998). Stereotyping and its threats are real. American Psychologist, 53, 680-681.doi: 10.1037//0003-066x.53.6.680

Steele, C. M., \& Aronson, J. (1995). Stereotype threat and the intellectual test performance of African Americans. Journal of Personality and Social Psychology, 69, 797-811.doi: 10.1037//00223514.69.5.797

Wong, J. T., \& Gallo, D. A. (2018). Activating aging stereotypes increases source recollection confusions in older adults: Effect at encoding but not retrieval. The Journals of Gerontology: Series $B, 74$, 633-641. doi:10.1093/geronb/gbx103 